\title{
A comparison of standard and high-dose regimens for the initiation of amiodarone therapy
}

\begin{abstract}
The effects of two regimens for the initiation of amiodarone therapy were compared in 92 patients with inducible sustained ventricular tachycardia (VT) at baseline electrophysiologic testing. Two groups of $\mathbf{4 6}$ patients each received a total of $\mathbf{1 6 . 8} \mathrm{gm}$ of oral amiodarone before follow-up electrophysiologic testing. Group A (standard dose) received $1200 \mathrm{mg} /$ day for 14 days, and group $B$ (high dose) received $2400 \mathrm{mg} /$ day for 7 days. Amiodarone suppressed the induction of sustained VT in six subjects $(13 \%)$ in group A versus $10(22 \%)$ in group $B(p=N S)$. In subjects who continued to have inducible VT after amiodarone loading, the mean increase in cycle length of induced VT was similar in group $A(\Delta=85 \pm 73 \mathrm{msec})$ and group $B(\Delta=78 \pm 59$ msec). The mean increase in sinus cycle length, AH and HV intervals, paced QRS duration, and ventricular refractory periods was also not significantly different between the two groups. Side effects developed in $10(22 \%)$ patients in group B but were serious only in one, and one patient required a reduction in dosage. Thus compared to the 14-day standard-dose regimen, the 7-day high-dose regimen was well tolerated and had similar effects on VT inducibility and electrophysiologic variables. Its use may significantly shorten the duration of hospitalization in patients with life-threatening inducible VT who are undergoing loading with amiodarone on an inpatient basis. (AM HEART J 1992;124:366.)
\end{abstract}

Joni Summitt, MD, Fred Morady, MD, and Alan Kadish, MD Ann Arbor, Mich.

Amiodarone is a widely used agent for the treatment of life-threatening ventricular arrhythmias. Results of several studies have shown electrophysiologic testing to be useful in predicting clinical responses in patients treated with amiodarone. ${ }^{1-7}$ Amiodarone possesses unusual pharmacokinetic properties, and a prolonged period of time is required to achieve its steady-state electrophysiologic effects. ${ }^{8,9}$ In an attempt to overcome a long delay in the onset of an antiarrhythmic effect, a period of high-dose loading has been recommended based on pharmacokinetic and clinical data. ${ }^{10-12} \mathrm{~A}$ frequently administered regimen consists of $1200 \mathrm{mg}$ given for 14 days before electropharmacologic testing. ${ }^{3,7}$ Because most patients receiving amiodarone have life-threatening arrhythmias, they are generally hospitalized during the loading phase. We hypothesized that the same total

From the Division of Cardiology, Department of Internal Medicine, University of Michigan Medical Center.

Supported in part by National Institutes of Health First Award HL.40667 (Dr. Kadish).

Received for publication Dec. 10, 1991; accepted Jan. 24, 1992.

Reprint requests: Alan H. Kadish, MD, Northwestern Memorial Hospital, 250 E. Superior St., Suite 524, Chicago, IL 60611.

4/1/38082 dosage of drug given over a shorter period of time might have similar efficacy and therefore shorten the hospitalization phase for amiodarone loading. This prospective study was designed to compare the effects of a loading regimen consisting of $2400 \mathrm{mg} /$ day of amiodarone for 7 days with those of a more typical regimen consisting of $1200 \mathrm{mg} /$ day for 14 days.

\section{METHODS}

Study patients. The patient population consisted of two groups of 46 patients each, who had spontaneous sustained ventricular tachycardia (VT) or ventricular fibrillation, symptomatic nonsustained VT or unexplained syncope in the setting of organic heart disease and inducible sustained monomorphic VT in the drug-free state. In addition, each patient had unsuccessful treatment with a class I antiarrhythmic drug and was thought to be an appropriate candidate for treatment with amiodarone. The clinical characteristics of the two groups are shown in Table I.

Electrophysiologic study protocol. Electrophysiologic studies were performed in the fasting nonsedated state after written informed consent was obtained. All subjects underwent a baseline study after antiarrhythmic drugs had been discontinued for at least five half-lives. Electrophysiologic testing was also performed after one of two oral amiodarone loading regimens. Two or more quadripolar electrode catheters were inserted via a femoral vein and positioned in the high right atrium and His bundle position 
Table I. Clinical characteristics

\begin{tabular}{|c|c|c|c|c|c|c|}
\hline \multirow[b]{2}{*}{ Variables } & \multicolumn{3}{|c|}{ Group A (standard dose) } & \multicolumn{3}{|c|}{ Group $B$ (high dose) } \\
\hline & Mean & $S D$ & Range & Mean & $S D$ & Range \\
\hline Age $(v x)$ & 64 & 9 & $42-81$ & 66 & 9 & $45-84$ \\
\hline \multirow[t]{2}{*}{ Ejection fraction $(s)$} & 29 & 9 & $14-52$ & 34 & 11 & $13-57$ \\
\hline & & No. & 5 & & No. & $\because$ \\
\hline \multicolumn{7}{|l|}{ Sex } \\
\hline Male & & 43 & 93 & & 42 & 91 \\
\hline Female & & 3 & 7 & & 4 & 9 \\
\hline \multicolumn{7}{|l|}{ Heart disease } \\
\hline Coronary disease & & 44 & 96 & & 45 & 98 \\
\hline Cardiomyopathy & & 2 & 4 & & 1 & 2 \\
\hline \multicolumn{7}{|l|}{ Clinical arrhythmia } \\
\hline $\mathrm{VT} / \mathrm{VF}$ & & 29 & 63 & & 32 & 70 \\
\hline Syncope \pm NSVT & & 8 & 17 & & 11 & 24 \\
\hline NSVI' without syncope & & 9 & 20 & & 3 & 6 \\
\hline
\end{tabular}

NSVT. Nonsustained ventricular tachycardia; $V T / V F$, sustained ventricular tachycardia or ventricular fibrillation.

and later repositioned in the right ventricular apex and right ventricular outflow tract. Blood pressure was continuously monitored via a femoral artery catheter. Intracardiac electrograms and ECG leads were recorded with a Siemens-Elema Mingograf-7 recorder (Siemens Pacesetter Inc., Sylmar, Calif.). ECG leads V 1 , I, and III were recorded during the stimulation protocol. For measurements of QRS and QT duration, the six standard limb leads were recorded. A programmable stimulator (Bloom Associates Ltd., Reading, Pa.) was used to deliver pacing stimuli of 2 msec duration at twice diastolic threshold.

The stimulation protocol used for initiating VT consisted of scanning early diastole with one to three extrastimuli during ventricular pacing at drive cycle lengths of 600,500 , and $400 \mathrm{msec}$ at the right ventricular apex and right ventricular outflow tract. Coupling intervals were limited to $200 \mathrm{msec}$ in all but one patient to minimize the induction of nonclinical arrhythmias. In that patient a coupling interval of $180 \mathrm{msec}$ reproducibly induced monomorphic VT, which was similar to that patient's spontaneous morphology. End points of the study were completion of the stimulation protocol or the reproducible induction of sustained monomorphic VT. Criteria for a positive results baseline electrophysiologic tests included induction of sustained VT or hypotensive VT requiring termination before 30 seconds. Criteria for an acceptable response to amiodarone at follow-up electrophysiologic testing were the elimination of inducible tachycardia or slowing of induced VT to a cycle length of greater than $350 \mathrm{msec}$ associated with a mean blood pressure greater than or equal to $80 \mathrm{~mm}$ of $\mathrm{Hg}$. Even if a well-tolerated VT was induced during electropharmacologic testing, the stimulation protocol was completed to determine whether other more rapid VT morphologies could also be induced.

The electrophysiologic parameters assessed at each study included sinus cycle length, AH, HV, and QT intervals during sinus rhythm and during atrial pacing at a cycle length of $600 \mathrm{msec}$, QRS duration measured on the fifteenth beat of ventricular pacing at cycle lengths of 600 and
$350 \mathrm{msec}$, and ventricular effective and functional refractory periods (measured at the right ventricular apex) at drive cycle lengths of 600 and 400 msec. For the determination of ventricular refractory periods, an eight-beat drive train and a 4-second intertrain pause were used. A conditioning period of 1 minute with drive trains and an intertrain pause was used before determination of refractoriness was begun. The $S_{1}-S_{2}$ coupling interval was decreased in 10 msec steps until $\mathrm{S}_{1}-\mathrm{S}_{2}$ failed to capture on two consecutive drive trains at a given coupling interval. In three patients in each group, measurements were not performed at a cycle length of $600 \mathrm{msec}$ because of sinus tachycardia.

Amiodarone administration. After baseline electrophysiologic testing, amiodarone was administered orally by means of one of two dosing regimens, both of which consisted of a total dose of $16.8 \mathrm{gm}$ of amiodarone during the loading phase. Group A (standard dose) consisted of 46 patients who received a dosage of $1200 \mathrm{mg} /$ day for 14 days before repeating the electrophysiologic studies. These were 46 consecutive patients who had been treated in our institution who met the inclusion criteria. The next 46 patients were prospectively treated with high-dose amiodarone. They constituted group B (high dose), which consisted of the next 46 patients who met the inclusion criteria and received $2400 \mathrm{mg} /$ day of amiodarone for 7 days before repeating the electrophysiologic studies. In addition, 28 subjects from group B who continued to have inducible hemodynamically unstable monomorphic VT after 1 week of high-dose loading were continued to take $2400 \mathrm{mg} /$ day of amiodarone for another 7 days and underwent repeat electrophysiologic testing. Plasma concentrations of amiodarone were determined at the time of serial electrophysiologic studies. In group B side effects were recorded at the time of follow-up electrophysiologic tests.

Definitions. Sustained VT was defined as lasting more than 30 seconds or requiring termination before 30 seconds because of hemodynamic compromise. Nonsustained VT was defined as tachycardia six complexes to 30 seconds in duration. Monomorphic VT had a constant beat-to-beat 


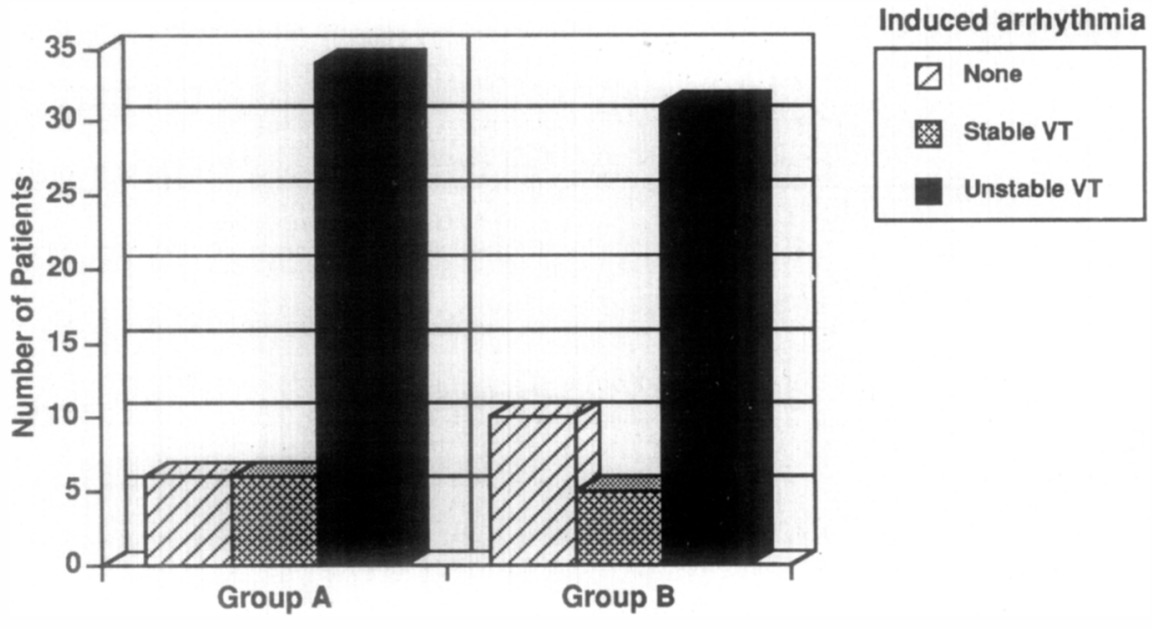

Fig. 1. Number of patients in group A and group B who had no inducible ventricular tachycardia (VT) (hatched bars), hemodynamically well-tolerated VT induced (shaded bars), or rapid VT induced (solid bars) during follow-up electrophysiologic study on amiodarone therapy. There were no significant differences between groups.

QRS morphology when viewed simultaneously in at least three leads. The ventricular effective refractory period was defined as the longest $S_{1}-S_{2}$ coupling interval that reproducibly failed to elicit a ventricular response. The ventricular functional refractory period was defined as the shortest $V_{1}-V_{2}$ interval obtained during delivery of single ventricular extrastimuli.

Data analysis. Intervals were measured at paper speeds of 100 to $250 \mathrm{~mm} / \mathrm{sec}$. AH, HV, and QT intervals, cycle length of induced VT, and paced QRS duration were determined to the nearest $5 \mathrm{msec}$. All measurements were made by a single observer (J. S.). The cycle length of induced VT was determined 5 seconds after its initiation. The change in cycle length of induced VT at serial electrophysiologic studies was compared in two ways: change in cycle length of VTs with similar morphologies (if present) and change in cycle length of the fastest VT induced. Chisquare analysis was used to compare inducibility and change in cycle length of induced VT. Analysis of variance was used to compare electrophysiologic parameters between groups $\mathrm{A}$ and $\mathrm{B}$, as well as the changes from baseline to 1- and 2-week studies in group B. In comparing changes within group B from the 1 -week to the 2 -week study, only data from patients who underwent a 2 -week study were used. Data are presented as mean \pm standard deviation. A $p$ value of less than 0.05 was considered statistically significant.

\section{RESULTS}

Effects on the induction of ventricular tachycardia. Amiodarone prevented the induction of sustained VT in 6 of $46(13 \%)$ patients in group A versus 10 of $46(22 \%)$ in group B ( $p=$ NS; Fig. 1$)$. The sustained monomorphic VT induced during electrophysiologic testing on a regimen of amiodarone therapy was hemodynamically well tolerated in six additional pa- tients in group A. The 12 patients with a favorable response to the drug were discharged on a regimen of chronic oral amiodarone therapy. 'The remaining 34 patients in group A were treated with combination antiarrhythmic drug therapy or an implantable cardioverter-defibrillator. Among the 36 patients in group B who continued to have inducible sustained monomorphic VT after 1 week of amiodarone therapy, 28 with poorly tolerated VT underwent an additional week of high-dose amiodarone loading followed by electrophysiologic study (see below), two underwent placement of an implantable cardioverter-defibrillator, five with hemodynamically tolerated inducible VT were discharged on a regimen of amiodarone, and one with induced hemodynamically unstable VT underwent a repeat study at another institution.

Effects on ventricular tachycardia cycle length. Amiodarone increased the cycle length of the fastest VT induced from $271 \pm 45 \mathrm{msec}$ to $356 \pm 76 \mathrm{msec}$ in 25 patients in group $\mathrm{A}(\Delta=85 \pm 73 \mathrm{msec} ; p<0.01)$ and from $264 \pm 52 \mathrm{msec}$ to $342 \pm 68 \mathrm{msec}$ in 20 patients in group B $(\Delta=78 \pm 59 \mathrm{msec} ; p<0.01)$. The increase in cycle length of induced VT was similar in the two groups. When considering only VT of the same morphology, amiodarone increased the cycle length of induced VT from $280 \pm 48 \mathrm{msec}$ to $374 \pm 83$ msec in group A $(\Delta=92 \pm 66 \mathrm{msec} ; p<0.01)$ and from $270 \pm 56 \mathrm{msec}$ to $356 \pm 92 \mathrm{msec}(\Delta=85 \pm 53$ msec; $p<0.01$ ) in group B. Once again the changes in cycle length produced by both loading dose regimens were similar. The proportion of subjects who demonstrated an increase in tachycardia cycle length of at least $100 \mathrm{msec}$ was also not significantly differ- 
Table II. Comparison of effects on electrophysiologic parameters in group A and group B

\begin{tabular}{|c|c|c|c|c|c|c|}
\hline \multirow[b]{2}{*}{ Parameters } & \multicolumn{3}{|c|}{ Group $A$} & \multicolumn{3}{|c|}{ Group $B$} \\
\hline & Baseline & 2 weeks & Change & Baseline & 1 week & Change \\
\hline $\mathrm{SCL}$ & $786 \pm 158$ & $899 \pm 160$ & $108 \pm 146^{*}$ & $829 \pm 103$ & $941 \pm 128$ & $113 \pm 137^{*}$ \\
\hline \multicolumn{7}{|l|}{$\mathrm{AH}$ interval } \\
\hline $\mathrm{SR}$ & $101 \pm 30$ & $127 \pm 28$ & $26 \pm 27^{*}$ & $96 \pm 28$ & $120 \pm 34$ & $23 \pm 16^{*}$ \\
\hline Paced $600 \mathrm{msec}$ & $121 \pm 49$ & $209 \pm 97$ & $84 \pm 78^{*}$ & $118 \pm 41$ & $201 \pm 85$ & $85 \pm 72^{*}$ \\
\hline \multicolumn{7}{|l|}{$\mathrm{HV}$ int erval } \\
\hline $\mathrm{SR}$ & $56 \pm 11$ & $61 \pm 11$ & $6 \pm 8$ & $50 \pm 8$ & $57 \pm 9$ & $7 \pm 8^{*}$ \\
\hline Paced $600 \mathrm{msec}$ & $55 \pm 12$ & $64 \pm 14$ & $9 \pm 10^{*}$ & $50 \pm 7$ & $59 \pm 10$ & $9 \pm 9^{*}$ \\
\hline \multicolumn{7}{|l|}{ QT interval } \\
\hline SR & $383 \pm 33$ & $456 \pm 49$ & $72 \pm 38^{*}$ & $393 \pm 34$ & $480 \pm 55$ & $86 \pm 53^{*}$ \\
\hline Paced 600 msec & $367 \pm 32$ & $432 \pm 40$ & $63 \pm 36^{*}$ & $375 \pm 29$ & $453 \pm 49$ & $77 \pm 46^{*}$ \\
\hline \multicolumn{7}{|l|}{ QRS duration } \\
\hline Paced $600 \mathrm{msec}$ & $169 \pm 22$ & $200 \pm 26$ & $31 \pm 18^{*}$ & $166 \pm 22$ & $199 \pm 26$ & $33 \pm 22^{*}$ \\
\hline Paced $350 \mathrm{msec}$ & $168 \pm 21$ & $218 \pm 34$ & $49 \pm 26^{*}$ & $168 \pm 23$ & $216 \pm 42$ & $48 \pm 33^{*}$ \\
\hline \multicolumn{7}{|l|}{ VERP } \\
\hline 600 rnsec DCL & $257 \pm 18$ & $288 \pm 19$ & $31 \pm 20^{*}$ & $260 \pm 20$ & $295 \pm 20$ & $34 \pm 30^{*}$ \\
\hline $400 \mathrm{msec} \mathrm{DCL}$ & $237 \pm 16$ & $267 \pm 18$ & $29 \pm 21^{*}$ & $242 \pm 20$ & $278 \pm 29$ & $36 \pm 35^{*}$ \\
\hline \multicolumn{7}{|l|}{ VFRP } \\
\hline $600 \mathrm{msec}$ DCL & $284 \pm 17$ & $317 \pm 18$ & $33 \pm 23^{*}$ & $283 \pm 19$ & $322 \pm 22$ & $39 \pm 26^{*}$ \\
\hline $400 \mathrm{msec}$ DCL & $261 \pm 16$ & $292 \pm 19$ & $31 \pm 20^{*}$ & $265 \pm 18$ & $297 \pm 20$ & $32 \pm 22^{*}$ \\
\hline
\end{tabular}

$D C L$, Drive cycle length; $S R$, sinus rhythm; $S C L$, sinus cycle length; $V E R P$, ventricular effective refractory period; $V F R P$, ventricular functional refractory period.

$p=\mathrm{NS}$ for all comparisons of change in group A versus group B.

${ }^{*} p<0.05$ baseline versus follow-up study.

ent between the two groups both with regard to the fastest tachycardia induced ( $45 \%$ of group $\mathrm{A}$ vs $36 \%$ of group B) and induced tachycardias of similar morphology ( $50 \%$ of group A vs $35 \%$ of group B).

Effects on ventricular conduction and refractoriness (Table II). Amiodarone significantly increased the paced QRS duration and ventricular refractory periods in both groups of patients. The effects of amiodarone on paced QRS duration were rate dependent and similar for the two dosing regimens. At a paced cycle length of $600 \mathrm{msec}, \mathrm{QRS}$ duration increased by $31 \pm 18 \mathrm{msec}$ in group A versus $33 \pm 22 \mathrm{msec}$ in group B $(p=\mathrm{NS})$. At a paced cycle length of 350 msec, QRS duration increased by $49 \pm 26 \mathrm{msec}$ in group A versus $48 \pm 33 \mathrm{msec}$ in group $\mathrm{B}(p=\mathrm{NS})$. Likewise the increase in ventricular effective and functional refractory periods measured at drive cycle lengths of 600 and $400 \mathrm{msec}$ were similar in the two groups. For example, at a drive cycle length of 600 msec, the effective refractory period increased from $257 \pm 18 \mathrm{msec}$ to $288 \pm 19 \mathrm{msec}(\Delta=31 \pm 20 \mathrm{msec}$; $p<0.01$ ) in group A versus from $260 \pm 20 \mathrm{msec}$ to $295 \pm 20 \mathrm{msec}(\Delta=34 \pm 30 \mathrm{msec} ; p<0.01)$ in group B ( $p=$ NS for group A vs group B).

Other electrophysiologic effects (Table II). Amiodarone significantly increased the sinus cycle length and $\mathrm{AH}, \mathrm{HV}$, and QT intervals in both groups of patients. Once again the changes in the two groups were similar. After amiodarone therapy the sinus cycle length increased by $108 \pm 146 \mathrm{msec}$ in group A versus $113 \pm 137 \mathrm{msec}$ in group B. During sinus rhythm there was an increase in the AH interval of $26 \pm 27$ msec in group A versus $23 \pm 16 \mathrm{msec}$ in group $B$, an increase in the $\mathrm{HV}$ interval of $6 \pm 8 \mathrm{msec}$ in group $\mathrm{A}$ versus $7 \pm 8 \mathrm{msec}$ in group $\mathrm{B}$, and an increase in the QT interval of $72 \pm 38 \mathrm{msec}$ in group A vs $85 \pm 53$ msec in group B. During atrial pacing at a cycle length of $600 \mathrm{msec}$, there was no significant difference in effect on these same parameters between the two groups.

Amiodarone effects in group B (Table III). Among the 28 subjects in group $B$ who received a second week of therapy with a dose of $2400 \mathrm{mg} /$ day because of an inadequate response to 1 week of therapy, two additional subjects had suppression of inducible sustained VT at the 2-week study. Five additional patients had only hemodynamically well-tolerated VT induced at the 2-week study. Thus 7 of 28 patients $(25 \%)$ who did not have a favorable response after 1 week of amiodarone therapy had one after 2 weeks of therapy. As noted previously, all electrophysiologic variables measured increased significantly from the baseline electrophysiology test to that performed after 1 week of loading with amiodarone. For some variables there was a continued effect of amiodarone in group $B$ when results of 1 and 
Table III. Comparison of electrophysiologic effects of amiodarone within group B

\begin{tabular}{|c|c|c|c|c|c|}
\hline Effects & Baseline & 1 week & Change & 2 weeks & Change \\
\hline Fastest VT CL & $257 \pm 47$ & $320 \pm 42$ & $63 \pm 50$ & $365 \pm 55$ & $45 \pm 38^{*}$ \\
\hline Same VT CL & $261 \pm 42$ & $374 \pm 94$ & $113 \pm 110$ & $398 \pm 55$ & $24 \pm 92$ \\
\hline Sinus CL & $835 \pm 96$ & $957 \pm 143$ & $123 \pm 136$ & $983 \pm 151$ & $26 \pm 91$ \\
\hline \multicolumn{6}{|l|}{$\mathrm{AH}$ interval } \\
\hline $\mathrm{SR}$ & $93 \pm 18$ & $117 \pm 26$ & $24 \pm 17$ & $123 \pm 31$ & $b \pm 22$ \\
\hline Paced $600 \mathrm{msec}$ & $122 \pm 34$ & $203 \pm 67$ & $80 \pm 63$ & $214 \pm 71$ & $11 \pm 63$ \\
\hline \multicolumn{6}{|l|}{$\mathrm{HV}$ interval } \\
\hline $\mathrm{SR}$ & $49 \pm 7$ & $56 \pm 9$ & $7 \pm 7$ & $60 \pm 10$ & $4 \pm 12^{*}$ \\
\hline Paced $600 \mathrm{msec}$ & $49 \pm 7$ & $59 \pm 10$ & $10 \pm 8$ & $62 \pm 11$ & $3 \pm 7$ \\
\hline \multicolumn{6}{|l|}{ QT interval } \\
\hline $\mathrm{SR}$ & $388 \pm 37$ & $474 \pm 55$ & $87 \pm 58$ & $497 \pm 60$ & $23 \pm 53$ \\
\hline Paced $600 \mathrm{msec}$ & $368 \pm 28$ & $451 \pm 52$ & $83 \pm 54$ & $469 \pm 52$ & $18 \pm 45$ \\
\hline \multicolumn{6}{|l|}{ QRS duration } \\
\hline Paced $600 \mathrm{msec}$ & $165 \pm 25$ & $196 \pm 29$ & $31 \pm 21$ & $209 \pm 31$ & $13 \pm 20^{*}$ \\
\hline Paced $350 \mathrm{msec}$ & $168 \pm 26$ & $212 \pm 46$ & $44 \pm 35$ & $236 \pm 41$ & $24 \pm 28^{*}$ \\
\hline \multicolumn{6}{|l|}{ VERP } \\
\hline $600 \mathrm{msec}$ DCL & $257 \pm 22$ & $297 \pm 20$ & $40 \pm 30$ & $297 \pm 24$ & 0 \\
\hline $400 \mathrm{msec}$ DCL & $237 \pm 21$ & $279 \pm 33$ & $43 \pm 41$ & $274 \pm 20$ & $5 \pm 36$ \\
\hline \multicolumn{6}{|l|}{ VFRP } \\
\hline $600 \mathrm{msec}$ DCL & $280 \pm 21$ & $324 \pm 23$ & $43 \pm 29$ & $325 \pm 25$ & $1 \pm 17$ \\
\hline 400 msec DCL & $260 \pm 18$ & $295 \pm 19$ & $35 \pm 23$ & $298 \pm 22$ & $3 \pm 19$ \\
\hline
\end{tabular}

$C L$, Cycle length; $D C L$, drive cycle length; $S R$, sinus rhythm; $V E R P$, ventricular effective refractory period; $V F R P$, ventricular functional refractory period. $p<0.05$ or all comparisons baseline versus 1 week.

${ }^{*} p<0.051$ week versus 2 weeks.

2 weeks of high-dose loading were compared. The cycle length of the fastest VT induced increased from $320 \pm 42$ msec after 1 week of high-dose amiodarone loading to $365 \pm 55 \mathrm{msec}$ after 2 weeks of high-dose loading $(p<0.05)$. The HV interval during sinus rhythm increased from $56 \pm 9 \mathrm{msec}$ at 1 week to $60 \pm 10 \mathrm{msec}$ after 2 weeks $(p<0.05)$. There was also a continued effect on ventricular conduction seen after 2 weeks of high-dose loading. During ventricular pacing at a cycle length of $600 \mathrm{msec}$, the QRS duration increased from $196 \pm 29$ msec after 1 week to $209 \pm 31 \mathrm{msec}$ after 2 weeks $(p<0.05)$. A significant continued effect was also seen during ventricular pacing at a cycle length of $350 \mathrm{msec}$.

Only eight subjects had a tachycardia of similar morphoogy induced at baseline and at the 1- and 2-week electrophysiologic tests. No significant increase in tachycardia cycle length was seen in this small group. However, six of eight patients did demonstrate a progressive increase in cycle length of induced VT. Values for individual patients are shown in Fig. 2. In addition, no significant change was seen between the 1- and 2-week studies in the following electrophysiologic parameters: sinus cycle length, $\mathrm{AH}$ interval, $\mathrm{HV}$ interval during atrial pacing, QT interval, or ventricular effective or functional refractory periods.

Plasma amiodarone concentrations. The plasma ami- odarone concentration was significantly higher $(2.5 \pm 1.1 \mu \mathrm{g} / \mathrm{ml})$ after 1 week of oral loading with $2400 \mathrm{mg} /$ day of amiodarone than after 2 weeks of loading with a daily dose of $1200 \mathrm{mg} /$ day $(1.6 \pm 0.6$ $\mu \mathrm{g} / \mathrm{ml})(p=0.0001)$. Although amiodarone concentrations continued to rise after 2 weeks of high-dose loading (to $2.7 \pm 1.5 \mu \mathrm{g} / \mathrm{ml}$ ), the change was not significant when compared to the 1-week levels. Serum des-ethylamiodarone levels measured after 1 week of high-dose loading $(0.89 \pm 0.36 \mu \mathrm{g} / \mathrm{ml})$ were not significantly different from levels after 2 weeks in group A $(0.85 \pm 0.26 \mu \mathrm{g} / \mathrm{ml})$. In contrast to amiodarone, des-ethylamiodarone levels within group B were significantly higher after 2 weeks of high-dose loading $(1.25 \pm 0.36 \mu \mathrm{g} / \mathrm{ml})$ than after 1 week.

Adverse effects within group B. During the first week of high-dose loading, the following adverse effects were seen: nausea ( 4 of 46), nausea and tremor ( 1 of 46 ), nausea and lethargy ( 1 of 46 ), tremor alone ( 1 of 46), dizziness ( 1 of 46 ), and congestive heart failure ( 1 of 46). One of the patients with nausea required dose reduction. During the second week of high-dose loading, 1 of 28 patients who had tremor required dose reduction and 1 of 28 who had tremor and nausea required dose reduction. One patient who received $2400 \mathrm{mg} /$ day of amiodarone for 14 days had adult respiratory distress syndrome 18 days after beginning amiodarone therapy. Results of a transbron- 
chial biopsy showed only infiltration of inflammatory cells, and the syndrome resolved over 2 weeks. However, for the purposes of this study the patient is considered to have had amiodarone pulmonary toxicity. Thus although the incidence of side effects with a regimen of $2400 \mathrm{mg} /$ day was $22 \%$, only one was serious and only one required a reduction in dosage during the loading phase.

\section{DISCUSSION}

Major findings. The major finding of this study is that suppression of inducible VT by amiodarone can be achieved in a similar proportion of patients if a loading dose of $16.8 \mathrm{gm}$ is given over either 7 or 14 days. In addition, both loading regimens produced similar changes in the electrophysiologic parameters measured in this study. A daily dose of $2400 \mathrm{mg} /$ day of amiodarone was well tolerated in the majority of patients. This rapid high-dose loading regimen has the potential for shortening the period of hospitalization during the initiation of amiodarone therapy for VT.

Regimens for oral amiodarone loading. Single-dose pharmacokinetic data have shown amiodarone to have a very large volume of distribution and a long terminal elimination half-life. ${ }^{12}$ These prolong the time necessary to reach steady-state tissue levels of the drug and result in a time lag between initiation of therapy and antiarrhythmic effect if therapy is initiated with maintenance doses of amiodarone. By use of noninvasive means to determine arrhythmia suppression, Rakita and Sobol ${ }^{11}$ showed that large initial doses of amiodarone were well tolerated and shortened the time needed to achieve arrhythmia control.

Up to 10 weeks of therapy with oral amiodarone is required to produce the electrophysiologic effects seen chronically. Kadish et al. $^{9}$ demonstrated that when the electrophysiologic effects of amiodarone rere compared between 2 weeks and 3 months of therapy, a progressive increase in the cycle length of induced VT and in the ventricular effective refractory period were noted. Other investigators have demonstrated similar results. ${ }^{3}$ To determine the time course of the onset of the electrophysiologic and antiarrhythmic effects of amindarone more precisely, Mitchell et al. ${ }^{13}$ performed serial electrophysiologic testing beginning 2 weeks after the initiation of a standardized oral loading regimen of amiodarone. The maximum effect on VT inducibility and cycle length was not seen until 10 weeks after initiation of therapy, well beyond the initial 2 weeks of high-dose loading.

It is not practical to hospitalize patients for 10

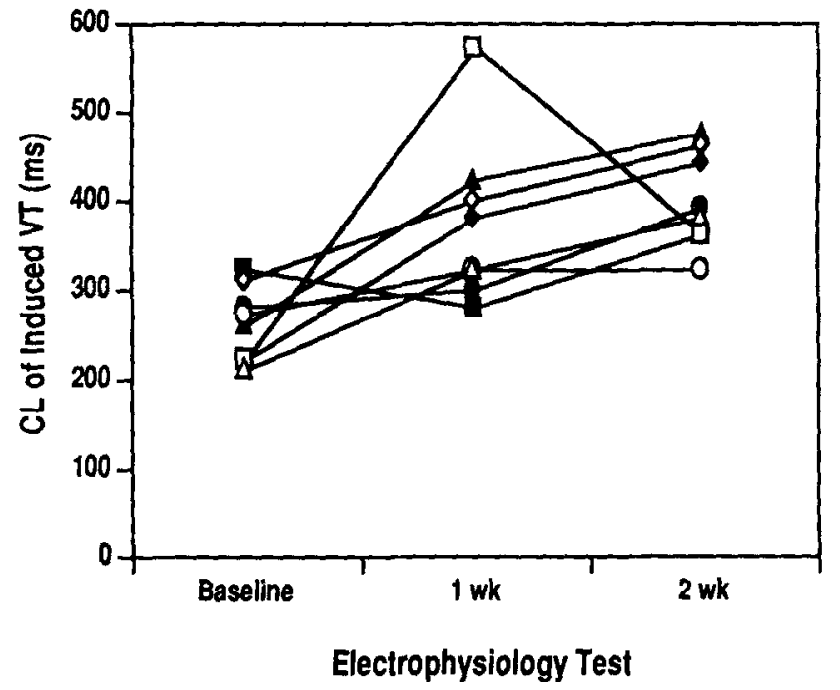

Fig. 2. Cycle length of ( $C L)$ of induced ventricular tachycardia (VT) in eight patients in group B who had VT of similar morphology induced during all three electrophysiologic tests. In six of eight patients, cycle length of induced VT increased progressively from baseline to 1 -week to 2 -week study. In one patient, cycle length of induced VT decreased from haseline to 1 -week study and then increased from the 1 -week to 2 -week study and then increased from baseline to 1 -week study and then decreased from 1 -week to 2 -week study. This patient also had second faster VT morphology induced and thus continued for second week of high-dose amiodarone.

weeks, and therefore in patients with life-threatening arrhythmias, "early" electrophysiologic testing has been utilized to determine whether it is safe to discharge patients on a regimen of oral amiodarone. ${ }^{1-3} \mathrm{~A}$ two-week loading period with oral amiodarone at a dosage of 600 to $1800 \mathrm{mg} /$ day has been used in most previous studies before electrophysiologic testing. ${ }^{1-8,14-19}$ Although Rosenfeld et al. ${ }^{20}$ performed electrophysiologic testing in 25 patients after 1 week of $1200 \mathrm{mg} /$ day of amiodarone, a comparison with a 2 -week loading regimen was not performed. A preliminary report published in 1984 compared 1- and 2 -week amiodarone loading regimens; however, that study has not yet appeared in expanded form. ${ }^{21}$ The total daily dose of amiodarone was limited to 1800 $\mathrm{mg} /$ day in the studies noted previously. However, Mostow et al. ${ }^{22}$ used up to $4.4 \mathrm{gm} /$ day to achieve rapid suppression of ventricular arrhythmias. Only 1 of 18 patients had serious side effects.

Electrophysiologic effects of the high-dose regimen. In the present study, 1 week of amiodarone therapy at a dosage of $2400 \mathrm{mg} /$ day produced significant increases in sinus cycle length, atrioventricular and ventricular conduction intervals, cycle length of induced VT, and ventricular refractory periods. 
These effects were similar to the effects of conventional loading regimens both in this and other studies. $^{3,9,13,23-27}$ In the 28 patients who received a second week of $2400 \mathrm{mg} /$ day of amiodarone, indexes of His-Purkinje and ventricular conduction (HV interval, QRS duration, and cycle length of induced VT) showed a progressive increase, whereas indexes of ventricular repolarization (ventricular effective refractory period, ventricular functional refractory period, and QT interval) did not.

Efficacy and toxicity of the high-dose regimen. Most prior studies have demonstrated that amiodarone only infrequently suppresses the induction of sustained VT at electropharmacologic testing. ${ }^{1-9,}$ 15, 16 For example, Horowitz et al. ${ }^{1}$ demonstrated that if 100 patients with inducible sustained VT at baseline electrophysiologic testing had coronary artery disease, only $20(20 \%)$ had the induction of sustained VT suppressed at electropharmacologic testing. Suppression of the induction of sustained VT was achieved in a similar percentage of patients in the present study (13\% with the standard-dose regimen and $22 \%$ with the high-dose regimen). In addition, amiodarone rendered the induced VT hemodynamically stable in several additional patients as demonstrated in prior studies. ${ }^{1,2}$

Although minor side effects were relatively frequent during the high-dose loading regimen, only one patient required a reduction in dosage during the loading phase. In addition, 4 days after the completion of 2 weeks of high-dose amiodarone therapy, one patient had apparent pulmonary toxicity. "Early" pulmonary toxicity has also been seen with a standard loading regimen. ${ }^{28}$ Three of 89 patients in one prior study had pulmonary toxicity during the first month of amiodarone therapy with a loading regimen that was generally $1400 \mathrm{mg} /$ day for 2 weeks. ${ }^{28}$ Thus our case of pulmonary toxicity does not appear to be unique to the high-dose loading regimen.

Limitations. The data presented concern only the acute loading phase of amiodarone therapy. No attempt was made to correlate results of electropharmacologic testing with long-term clinical outcome. Although the predictive value of electrophysiologic testing after 1 week of high-dose therapy has been presumed to be as good as after 2 weeks of therapy, this remains to be established. In addition, only two dosing regimens were compared in the present study. No conclusions regarding other potential loading regimens can be drawn from the present results.

Clinical implications. The need for amiodarone has been found to be a major determinant of the length of hospital stay and the cost in patients undergoing electrophysiologic testing because of the long period of time required for loading. ${ }^{27}$ Our findings suggest that a loading phase of $2400 \mathrm{mg} /$ day of amiodarone for 1 week may be clinically useful. This should result in a shortened hospitalization and substantial cost savings. Most patients who persist in having inducible hemodynamically unstable VT after 1 week of amiodarone therapy should receive alternative therapy, because the response rate to a second week of high-dose therapy is small. However, occasional patients who are poor candidates for other forms of therapy may benefit from treatment with an additional week of amiodarone.

\section{REFERENCES}

1. Horowitz LN, Greenspan AM, Spielman SR, Webb CR, Morganroth J, Rotmensch H, Sokoloff NM, Rae AP, Segal BL, Kay HR. Usefulness of electrophysiologic testing in evaluation of amiodarone therapy for sustained ventricular tachyarrhythmias associated with coronary heart disease. Am J Cardiol 1985;55:367-71.

2. Kadish AH, Buxton AE, Waxman HL, Flores B, Josephson ME, Marchlinski FE. Usefulness of electrophysiologic study to determine the clinical tolerance of arrhythmia recurrences during amiodarone therapy. J Am Coll Cardiol 1987;10:90-6.

3. Greenspon AJ, Volosin KJ, Greenberg RM, Jeffries L, Rotmensch HH. Amiodarone therapy: role of early and late electrophysiologic studies. J Am Coll Cardiol 1988;11:117-23.

4. Borggrefe M, Breithardt G, Seipel L. Value of serial electrophysiological testing in the treatment of ventricular tachyarrhythmias with amiodarone [Abstract]. Circulation 1983; 68:III-381.

5. Schmitt C, Brachmann J, Waldecker B, Rizos I, Senges J, Kubler W. Amiodarone in patients with recurrent sustained ventricular tachyarrhythmias: results of programmed stimulation and long-term clinical outcome of chronic treatment. AM HEART J 1987;114:279-82.

6. Zhu J, Haines DE, Lerman BB, DiMarco JP. Predictors of efficacy of amiodarone and characteristics of recurrence of arrhythmia in patients with sustained ventricular tachycardia and coronary artery disease. Circulation 1987;76:802-9.

7. Manolis AS, Uricchio F, Estes NAM. Prognostic value of early electrophysiologic studies for ventricular tachycardia recurrence in patients with coronary artery disease treated with amiodarone. Am J Cardiol 1989;63:1052-7.

8. Haffajee CI, Love JC, Canada AT, Lesko LJ, Asdourian G, Alpert JS. Clinical pharmacokinetics and efficacy of amiodarone for refractory tachyarrhythmias. Circulation 1983; 67:1347-55.

9. Kadish AH, Marchlinski FE, Josephson ME, Buxton AE Amiodarone: correlation of early and late electrophysiologic studies with outcome. AM HEART J 1986;112:1134-40.

10. Siddoway LA, McAllister CB, Wilkinson GR, Roden DM. Woosley RL. Amiodarone dosing: a proposal based on its pharmacokinetics. AM HEART J 1983;106:951-6.

11. Rakita L, Sobol SM. Amiodarone in the treatment of refractory ventricular arrhythmias: importance and safety of initial high-dose therapy. JAMA 1983;250:1293-5.

12. Holt DW, Tucker GT, Jackson PR, Storey GCA. Amiodarone pharmacokinetics. AM HEART J 1983;106:840-7.

13. Mitchell LB, Wyse G, Gillis AM, Duff HJ. Electropharmacology of amiodarone therapy initiation. Time courses of onset of electrophysiologic and antiarrhythmic effects. Circulation 1989;80:34-42.

14. Nademanee K, Singh BN, Hendrickson J, Intarachot V, Lopez B, Feld G, Cannom DS, Weiss JL. Amiodarone in refractory life-threatening ventricular arrhythmias. Ann Intern Med 1983;98:577-84. 
15. Hamer AW, Finerman Jr WB, Peter T, Mandel WJ. Disparity between the clinical and electrophysiologic effects of amiodarone in the treatment of recurrent ventricular tachyarrhythmias. AM HEART J 1981;102:992-8.

16. Waxman HL, Groh WC, Marchlinski FE, Buxion AE, Sadowski LM, Horowitz LN, Josephson ME, Kastor JA. Amiodarone for control of sustained ventricular tachyarrhythmia: clinical and electrophysiologic effects in 51 patients. Am J Cardiol 1982;50:1066-74.

17. Fogoros RN, Anderson KP, Winkle RA, Swerdlow CD, Mason JW. Amiodarone: clinical efticacy and toxicity in 96 patients with recurrent, drug-refractory arrhythmias. Circulation 1983; 68:88-94.

18. McGovern B, Garan H, Malacoff RF, DiMarco JP, Grant G, Seller TD, Ruskin JN. Long-term clinical outcome of ventricular tachycardia or fibrillation treated with amiodarone. Am J Cardiol 1984;58:1558-63.

19. Klein LS, Fineberg N, Heger JJ, Miles WM, Kammerling JM, Chang MS, Zips DP, Prystowsky EN. Prospective evaluation of a discriminant function for prediction of recurrent symptomatic ventricular tachycardia or ventricular fibrillation in coronary artery disease patients receiving amiodarone and having inducible ventricular tachycardia at electrophysiologic study. Am J Cardiol 1988;61:1024-30.

20. Rosenfeld LE, Kennedy EE, Pearlmutter RA, Bookbinder MJ, McPherson CA, Batsford WP. Dissociation of electrophysiologic and pharmacologic stability during an abbreviated ural loading regimen of aniodarone. AM HEART J 1987; 114:1367-74.
21. Prystowsky EN, Heger JJ, Miles WM, Zipes DP. Amiodarone: interrelationship of dose and time on electrophysiologic and antiarrhythmic effects [Abstract]. Circulation 1984;70(suppl II):3.

22. Mostow ND, Vrobel TR, Noon D, Rakita L. Rapid suppression of complex ventricular arrhythmias with high-dose oral amiodarone. Circulation 1986;73:1231-8.

23. Ferrick KJ, Reiffel JA, Bigger Jr JT, Livelli FD, Gliklich JI. Electrophysiologic effects of chronic amjodarone therapy [Abstract]. PACE 1984;7:480.

24. Zipes DP, Prystowsky EN, Heger JJ. Amiodarone: electrophysiologic actions, pharmacokinetics and clinical effects. $J$ Am Coll Cardiol 1984;3:1059-71.

25. Marchlinski FE, Buxton AE, Kindwall KE, Miller JM, Rosenthal ME, Gottlieb CD, Bloom RB, Josephson ME. Comparison of individual and combined effects of procainamide and amiodarone in patients with sustained ventricular tachyarrhythmias. Circulation 1988;78:583-91.

26. Mason JW, Hondeghem LM, Katzung BC. Amiodarone blocks inactivated cardiac sodium channels. Pflugers Arch 1983; 396:79-81.

27. Kay HR, Horowitz LN, Goldstein H, Tanida E, Mills LC, Greenspan AM, Spielman SR. Determinants of hospital cost and length of stay for patients undergoing electrophysiologic testing. Am J Cardiol 1987;60:298-302.

28. Margon SA, Lawrence EC, Wheeler SH, J, Lin, HT, Wyndham CRC. Amiodarone pulmonary toxicity: prospective evaluation of serial pulmonary function tests. J Am Coll Cardiol 1988; 12:781-8. 